\title{
New Hope for Our Planet: Space - Age Energy and a New Kondratieff Cycle
}

\author{
Gruber HCJ* \\ Honorary President of the German Association for Space Energy Association (DVR), An der Herberge 7, D-58119 Hagen, German
}

*Corresponding author: Gruber HCJ, Honorary President of the German Association for Space Energy Association (DVR), Ander Herberge 7, D-58119 Hagen, Germany, Tel: (0049) - (0) 23 34-32 13; Fax : (0049) -23 34-4 37 81, E-mail: josef.gruber@fernuni-hagen.de

Received date: March 28, 2015; Accepted date: March 30, 2015; Published date: April 07, 2015

Copyright: (c) 2015 Gruber HCJ. This is an open-access article distributed under the terms of the Creative Commons Attribution License, which permits unrestricted use, distribution, and reproduction in any medium, provided the original author and source are credited.

\section{Introduction}

The space energy technology (RET) uses the previously unused Erneuville - newable energy space (RE). It is everywhere, always and in virtually unlimited quantities available. RET is the most advantageous way to sustainability of energy supply worldwide. The widespread use of RET, that is, the energy space - age, may soon (you can say 2012) begin. This is, as in previous technological revolutions, to a new Kondratieff cycle füh-ren, ie to a longer-term economic recovery. As a result, many countries can accelerate out of the current economic crisis to come out.

I can summarized say about the collected since 1993 Information About RE / RET: Developments in RE / RET is greatly accelerated in recent years. The big breakthrough to the widespread application of RET is still missing, but there is reason to hope that this breakthrough soon come he still starts in 2012. RET is the most advantageous way to the sustainability of energy con-care are when many people use it worldwide. Then the air pollution can be greatly reduced by the present combustion-based power engineering. RE etc. be very competitive in comparison to the traditional renewable energy solar, wind, What-water and biomass, mainly because they and in virtually ignored cross-ter quantity, always ( 24 hours per day, 365 days per year) is available everywhere. The widespread introduction of RET offers great opportunities for investors. You can create many new jobs. It can lead to a new Kondratieff cycle, which is much more than a business cycle. RET can help humanity to come out of the current global economic crisis and rich, he's sustainability in the energy world. The RET insertion can also help in other areas (eg health-beauty / medicine) to achieve sustainability. But it will require the support of many Men-rule. Get active!

Solar, wind, hydro, geothermal and biomass are not the only renewable energy-energy resources! Prove the more recent research has shown that there is a more renewable energy, the energy space. You will also neutrino energy, Vakuumfeld-Energy, zero point energy, cosmic energy, free energy and ether-called energy. With appropriate method for energy recovery it can be used: These procedures today mostly as a space energy technologies (RET) refers. Similarly, positive effects of RET as one would expect from the "field force machine" (FKM), which is mounted quite different, according to Prof. Heinz Wenz, Frankfurt aM, but as

RET because they are "bonded magnet energy" uses. With a solid theoretical foundation is a device that uses the space energy, nor a perpetual motion machine like any other power plant that uses a different specifical source of energy: a solar power plant, solar energy, wind generators, wind energy, etc. RE devices operate i.d.R. always ( 24 hours per day, 365 days a year) and everywhere (on earth and in space). Consequently, ranging from relatively small RE devices. The need to save energy (now usually very expensive), will dramatically cuts the, especially if optimal control technique is used wisely. Since the energy space is available everywhere, even a decentralized energy supply is possible. This is especially important for developing countries, where it (power lines, etc.) are not yet a nationwide power grid. For these reasons, developed RE devices will be very competitive to ei-ner usable size. Taken together, as I know all developments in recent years allow op - timistic assessment: The transition of humanity in the space - age energy with respect to energy permanent (sustainable, sustainable) economic system is approaching. He can - we can say - begin later in 2012. Then, the widespread use of vacuumenergy technology (RET) is at the center. Also, contaminated sites (eg from nuclear energy use) will be eliminated by "new" transmutation techniques probable -lich -site (ie without Castor transports) and create new materials Ki -nen. RE utilization widespread will also allow poor developing countries, sustainable solutions to their energy problems.

The global RET introduction becomes a long-term economic recovery füh -ren, a new Kondratieff cycle. A Kondratieff cycle is much more than a "übli -cher" business cycle. A "usual" business cycle usually takes 8 - 10 Years, a cond - ratieff cycle 50 - 60 (or more) years. This means that comprises a Kondratieff cycle, for example, 5 "üb Liche" business cycles. He is i.d.R. triggered by a technological revolution, for example, by RET.

In the book by Leo A. Nefiodow, The sixth Kondratieff cycle, 6th ed. 2006 Rhein-Sieg-Verlag, St. Augustine (ISBN 3-9805144-5-5) we find the following information on Kondratieff cycles (Kozy):

1. Kozy: Beginning 1780: Steam Machine, Textile Industry $\rightarrow$ clothing.

2. Kozy: Beginning about 1830 to 1850 : railway, steel $\rightarrow$ mass transport.

3. Kozy: Beginning about 1870 to 1890: Electrical Engineering, Chemistry $\rightarrow$ mass consumption.

4. Kozy: Beginning about 1920 to 1935: automotive, aircraft, petrochemical $\rightarrow$ Individual mobility

5. Kozy: Beginning about 1950 - 1980: Information Technology $\rightarrow$ Information, Communication.

6. Kozy: Beginning about 2000 to 2005 (so Nefiodow): Biotechnology, psychosocial total

\section{$\rightarrow$ Health Holistic Health}

Nefiodow argues that health in a holistic sense - physically, emotionally, mentally, socially and ecologically - can be carriers in the 21 st century will be. After Nefiodows assessment, countries, regions, institutions and people who line up early on the 6th Kondratieff cycle, among the winners. In the aligned on holistic health 6 . Kondratieff cycle healthy diet play (eg organic products) and healthy lifestyle (eg organic cosmetics, "healthy" structure, avoidance of mobile phone 
radiation) play a central role. Also, energy medicine, informational medicine and homeopathy then the current health care system (often called the "Health System") change significantly. The 6th Kondratieff cycle, as described by Nefiodow can be substantially supplemented and reinforced by the very space energy technology (RET). One can well founded say: The specified by Nefiodow geared towards holistic health 6th Kondratieff cycle is a part of the first part, a "double" 6th Kondratieff cycle A second part is due to the widespread introduction of RET. You can lead the world to a particularly environmentally friendly economic recovery, the Overcoming so far still reinforcing the global economic crisis. One can also speak of a well-founded ecological Kondratieff cycle. By RE utilization of man-made part of climate change can be greatly reduced. Overall, the space technology is one of the largest, if not the largest tech-cal revolution in the history of mankind. If properly designed, the Raumener-energy era becomes a blessing for our planet and for all of humanity.

In the literature there are many references to working RET devices, but have been suppressed, particularly of financial oligarchs who kontrol - lose today's energy industry. Thus, for example, reliably reported that Nikola Tesla (1856 - 1943) in 1930 with a converted car, the luxury brand Pierce Arrow, without fuel from Buffalo (New York) to Niagara Falls drove (about $34 \mathrm{~km}$ ). But Tesla got from the financial world is no support for the further development of the new drive .As (Emeritus) Professor of Statistics and Econometrics I am an economist basically. Many readers of these lines will be wondering: How does an economist to to deal with Ener- giefragen, with spatial energy? I have been from an early age of the opinion that we need to work as a scientist, not only in Ivory tower that we have to deal with problems that affect the society, etc. So I began soon after the accident at the nuclear reactor at Chernobyl (April 1986) to conduct a major research project in which the cost-optimal energy mix for the FRG was calculated. (40 years, including traditional renewable energy, but not RET). The first demonstration of an (alleged) RET device I saw on 2 July 1993.

Since then, I try as an individual and as President (1997 - 2003) and Ehrenprä - President (since 2004) of the German Association for Space Energy Association (DVR) to facilitate the transition to RE - age, in particular through the production and sharing of information over RET, about the benefits of widespread RE - use and associated with the transition disadvantages (which have to be kept as small as possible). So I take, for example, every year in international conferences "around the globe" part. In addition, I help to establish contacts between scientists, inventors, engineers and sub - participants. I also like to hold talks on RE / RET, which are the economic and environmental aspects of RE experience in the foreground for me as an economist.

The space energy technology (RET) can complement and replace our current energy technology worldwide. The transition from vacuum-energy age is associated with a very large -shaping required if the disadvantages of transition should be minimized. The even- if very large room for maneuver, it is for the benefit of people and nature to use. To develop RE devices to a size and performance, as it is needed for wide - spread applications ver, is a big challenge, especially for engineering sciences. To produce world in a large number of items and is applicable, inter alia, create many jobs. This may allow existing sub growing company. It can also lead to many new businesses, new industries füh -ren. This offers great opportunities for investors.

The space energy has great advantages for people and nature. For example, then fah -ren car without the usual fuel today, heaters consume no fuel and no natural gas and electric power is generated quite "simple". The climate impact of energy technology has been greatly reduced. Taking all the advantages of the RE-use form strong incentives to use RE devices as soon as possible and thereby replace the now standard equipment (vehicle drives, heaters, generators, etc.) worldwide. This has far-reaching consequences. It is particularly important that shock-like drops in demand are in today's energy host society avoided or compensated by rapid change and cooperation: The faster for an energy sector (eg transport sector, power sector or heat generation sector) the required $\mathrm{RE}$ devices in the required large quantities without involvement of traditional companies offered this energy sector, the greater the Ge risk that occurs in the corresponding traditional energy sector to sudden Nachfrageein-breaks with many adverse consequences. As a result of the widespread Interdependenzen between different sectors of the economy of a country and between different countries - which can easily lead to hardly likely negative chain reactions. But in an advantageous design of the transition to REage are justifiable Hoff-nung, a new long-term economic recovery (Kondratieff cycle) to BEKOM-men. 